\title{
Surgical treatment of bilateral vanishing lung syndrome: a case report
}

Dmitry Borisovich Giller ${ }^{1 *}$, Galina Vladimirovna Scherbakova', Boris Dmitrievich Giller', Arkadyi Leybovich Khanin², Vladimir Nikolayeich Nikolenko ${ }^{3}$ and Mikhail Yegorovich Sinelnikov ${ }^{4}$ (D)

\begin{abstract}
Background: Volume reduction surgery is a routine treatment method for lung emphysema in chronic obstructive pulmonary disease (COPD) patients. The formation of giant bullous emphysema is an indication for surgical bullectomy. Bilateral giant bullae severely compromise lung function and complicate surgical treatment.

Case presentation: We present the algorithm for surgical treatment and correction of complications in a 38-yearold male with bilateral giant bullae (vanishing lung syndrome), severe COPD. Primarily the patient was admitted with a mild cough, mucopurulent sputum and dyspnea. A CT scan revealed bilateral giant bullae, displacing up to $50 \%$ of lung volume. A two-stage surgical bullectomy was planned, yet postoperative complications due to secondary bullae rupture prompted urgent revision with contralateral bullae resection. After complete bullectomy, severely reduced lung volume was successfully managed throughout a long postoperative rehabilitation period. At 5 year follow-up, spirometry indicators and radiological examination show significantly improved and stable lung function.
\end{abstract}

Conclusion: This clinical case demonstrates the technical difficulties and possible complications of extended bilateral lung resections in patients with severe vanishing lung syndrome. Single-stage treatment of bilateral giant bullous emphysema is recommended to minimize postoperative complications and reduce risk of bullae rupture. Positive long-term outcome outweighs possible complications of surgical treatment.

Keywords: Bullous emphysema, Gigantic lung bullae, VATS, Spontaneous pneumothorax, COPD surgery

\section{Background}

Chronic obstructive pulmonary disease (COPD) can present as bullous emphysema, which can lead to the formation of giant bullae. Though this is a rare phenomenon, giant emphysematous bullae, characteristic of "vanishing lung syndrome", can lead to formation of several giant air pockets, naturally expanding, displacing a significant amount of already compromised lung tissue. This leads to saturation related complications, as well as higher risk of infection and rupturing.

\footnotetext{
* Correspondence: giller-thorax@mail.ru

'M.I. Perelman Department of Phthisiopulmonology and Thoracic Surgery, I.M. Sechenov First Moscow State Medical University (Sechenov University), 119991, 8 Trubeckaya str., Moscow, Russia

Full list of author information is available at the end of the article
}

Vanishing lung syndrome usually presents as one or several giant emphysematous bullae, and is often accompanied by other lung tissue pathology, including smaller bullae and constrictive pathology. Rupturing of emphysematous type II bullae leads to spontaneous pneumothorax, and is the most frequent indication for emergency thoracic surgery in patients with COPD [1,2]. Giant bullae should be treated surgically. A large resection bullectomy a spontaneous pneumothorax can be caused by barotrauma due to lung ventilation or insufficient volume of primary lung resection when large bullae were located close to the resection line $[3,4]$. This requires thorough preoperative planning to account for possible complications. We present a clinical case of surgical treatment of bilateral giant bullae in a patient with COPD, written 
according to CARE case report guidelines. The treatment was complicated by a spontaneous pneumothorax due to an undiagnosed bulla underlying the giant emphysematous bulla. Urgent surgical treatment allowed for correction and stabilization of the patient.

\section{Case presentation}

A 38-year-old male with COPD and bullous pulmonary emphysema was admitted into the phthisiopulmonology department, complaining of a periodic cough with mucopurulent sputum in the morning, whistling in the lungs in horizontal position, shortness of breath during mild exercise, persistent fatigue. The patient had a number of lung health risk factors (such as a work on a mining truck, contact with dust agents of silicates, volatile substances, smoker), with no prior history of lung disease. Physical examination revealed an expiratory wheeze and fine crackles during forced expiration. Radiographically, giant thin-walled bullae were detected in both lungs, characteristic of vanishing lung syndrome [5-7]. Alpha-1 antitripsin deficiency was excluded ( $\alpha 1$ - antitrypsin levels were normal). Spirometry showed FEV1/VC ratio to be $<0.7$. Surgical treatment was advised with prior patient stabilization. Inhalation of Tiotropium bromide 5 mcg per day was prescribed. At the same time NYHA [8] class III (2 grade MRC) dyspnea persisted. A chest CT showed

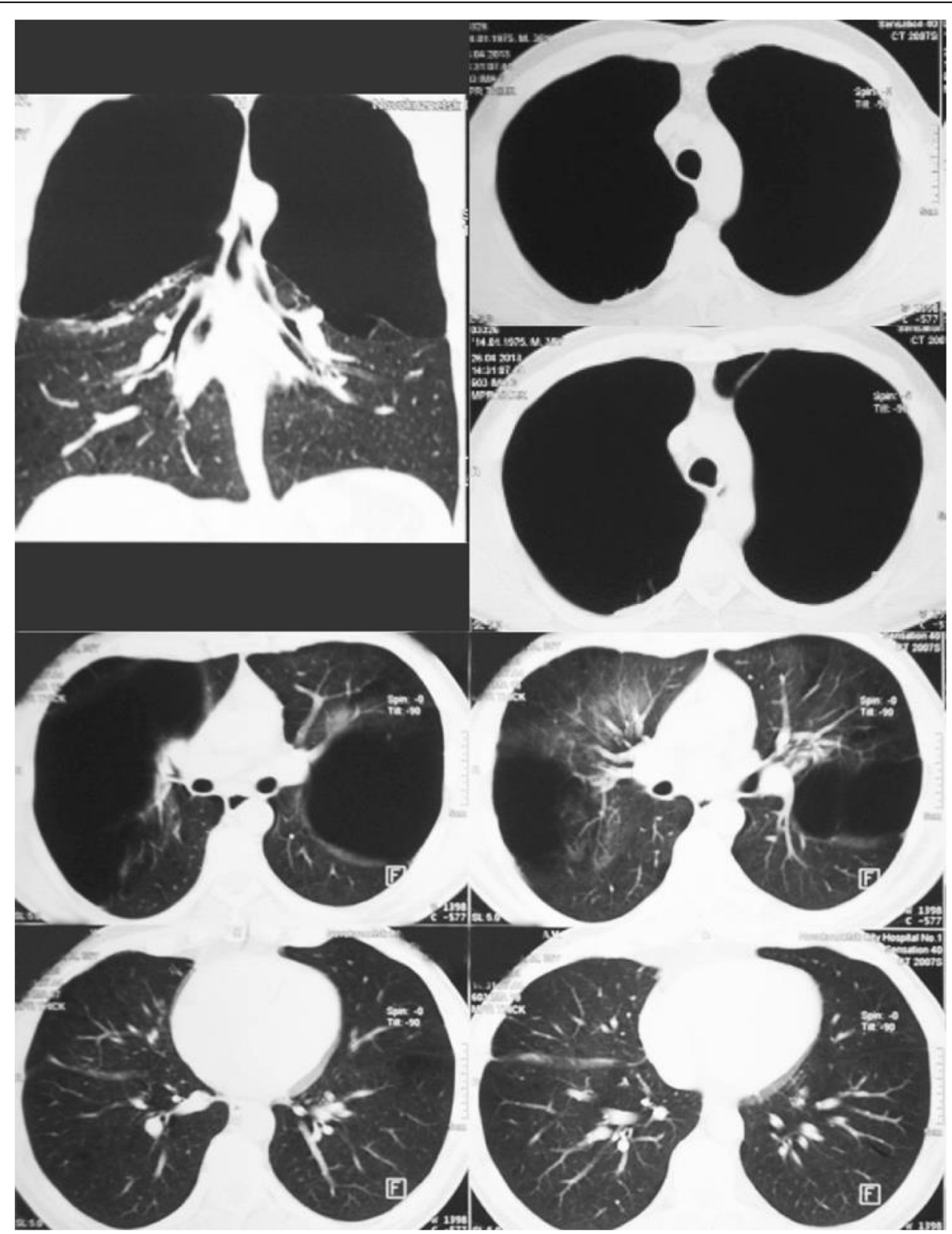

Fig. 1 Chest CT scan on admission. Upper sections of the both lungs contains gigantic bullae over $1 / 2$ of hemithorax volume. Pulmonary parenchyma in middle and lower sections is preserved, but emphysemateus. It contains singular bullae 
centrilobular emphysema and bilater giant emphysematous bullae (Fig. 1). Sputum fluorescent microscopy and bacteriological testing did not reveal acid-fast bacilli. Indications for surgical treatment were presented according to ERS/ATS criteria [9], taking into account respiratory failure progression and negative patient dynamics.

Surgical protocol consisted of a two-stage approach. Primarily, under combined endotracheal anesthesia with separate bronchial intubation, a VATS right upper lobectomy was performed. Surgery duration was $240 \mathrm{~min}$, blood loss was minimal $(30 \mathrm{ml})$. Complete right upper lobe excision allowed for the removal of a giant bulla (25 $\mathrm{cm}$ in diameter). Intraoperatively no complications occurred. $26 \mathrm{~h}$ after primary surgery the patient presented with acute respiratory distress, upon examination an acute spontaneous pneumothorax on the right with bullae hyperextension on the left (Fig. 2) was diagnosed. Respiratory failure progression $(\mathrm{pCO} 2=37.0 \mathrm{mmHg}$, $\mathrm{pO} 2=58 \mathrm{mmHg}$ ) prompted urgent surgery. A revisional surgery on the right and a left lobectomy (S1-2, S3) was planned. During surgery, a type II bulla $(7 \mathrm{~cm})$ rupture was revealed in the right lung outside the previous resection line, which caused the pneumothorax, a S6 reresection was performed with removal of the ruptured bulla. A S1-2, S3 anatomical resection was performed on the left lung with removal of a giant bulla $(25 \mathrm{~cm}$ in diameter). Surgery duration was $40 \mathrm{~min}$, total blood loss was $40 \mathrm{ml}$. Postoperatively the patient received respiratory exercise and pharmacological therapy (Olodaterol $5 \mathrm{mcg}$; Tiotropium bromide $5 \mathrm{mcg}$ ). Due to a large volume of resected lung tissue, slow pulmonary expansion was carried out to reduce the risk of pneumothorax and formation of new bullae. This required lengthy hospitalization with pleural drains removed 30 days after surgery. An artificial pneumoperitoneum aimed on reduction of intrapleural pressure to reduce pneumothorax risk and pulmonary tissue hyperextension.

The patient was discharged in a satisfactory condition 30 days after surgery, pulmonary pneumatization was satisfactory (Fig. 3). Wound closure was satisfactory (Fig. 4). Bullous emphysema was confirmed histologically. In addition to thin fibrotic bullae, pneumosclerosis and lung congestion was revealed: perivascular lymphoid infiltrates, vascular wall thickening, foci of atelectasis, emphysematous lung tissue, lymphoid tissue inhibition in lymph nodes, sites of fibrosis were identified histologically. Upon discharge, importance of quitting smoking, lung exercise and regular observation were thoroughly discussed with the patient.

At 5 years follow-up past the patient was smoke-free, physically active, overall condition was above satisfactory. I-II NYHA class dyspnea was present, no II tone accent over the pulmonary artery was present. Fine crackles during forced expiration were revealed mostly

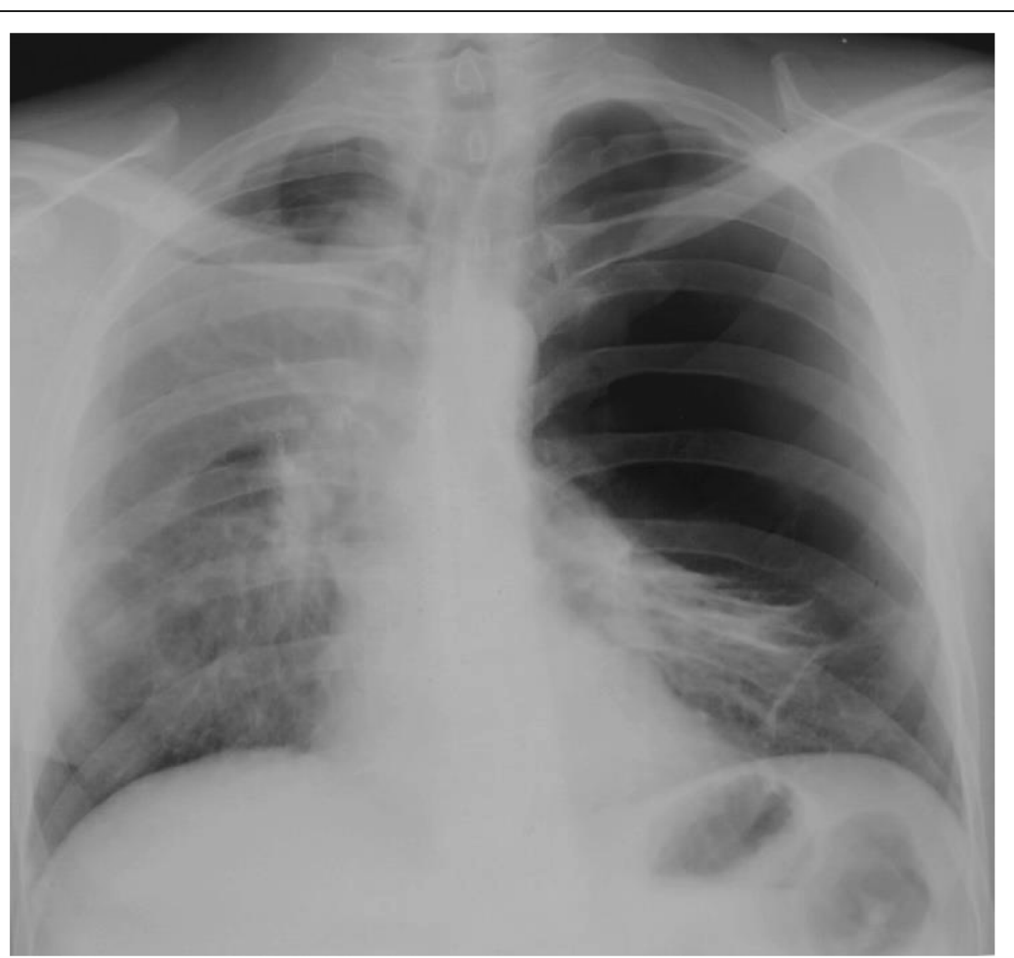

Fig. 2 Chest plain film past the first surgery. Giant bull on the right is enlarged and fills about 2/3 of hemithorax volume. Mediastinum is shifted to the right. Right lung is not extended 


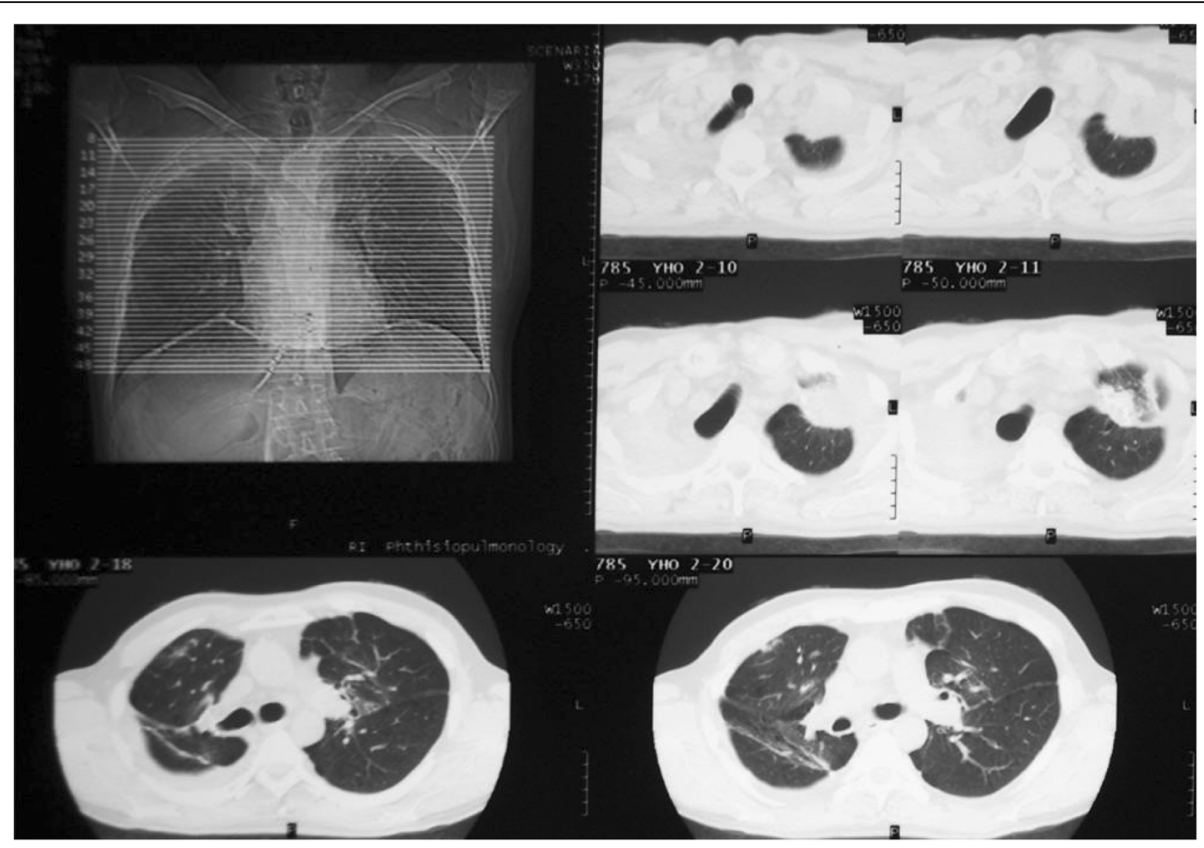

Fig. 3 CT scan on discharge. Both operated lungs are extended

on the right. ECG and echocardiogram showed no signs of pulmonary hypertension. Radiological examination showed few small bullae in the lungs, no giant bullae formation was observed (Fig. 5). No additional adverse events except several small bullae were found. Overall improved spirometry results were stable (Table 1).

\section{Discussion}

The formation of rapidly progressing riant emphysematous bullae is often associated with COPD progression $[1,10-12]$, and if combined with a FEV1 decrease to less than $25 \%$, may be an indication for lung transplantation [13]. Significant progressive reduction of spirometry indications and reduced exercise tolerance accompanied with dyspnea are characteristic to patients with vanishing lung syndrome (VLS). Surgical treatment is possible and effectively reduces dyspneic symptoms and significantly lowers the risk of spontaneous pneumothorax in patients with VLS [14]. Despite the associated risks of bulla recurrence, VATS bullectomy significantly improves patient respiratory function and reduces risks of serious complications associated with giant emphysematous bullae. Our case reports shows, that within a 5 year
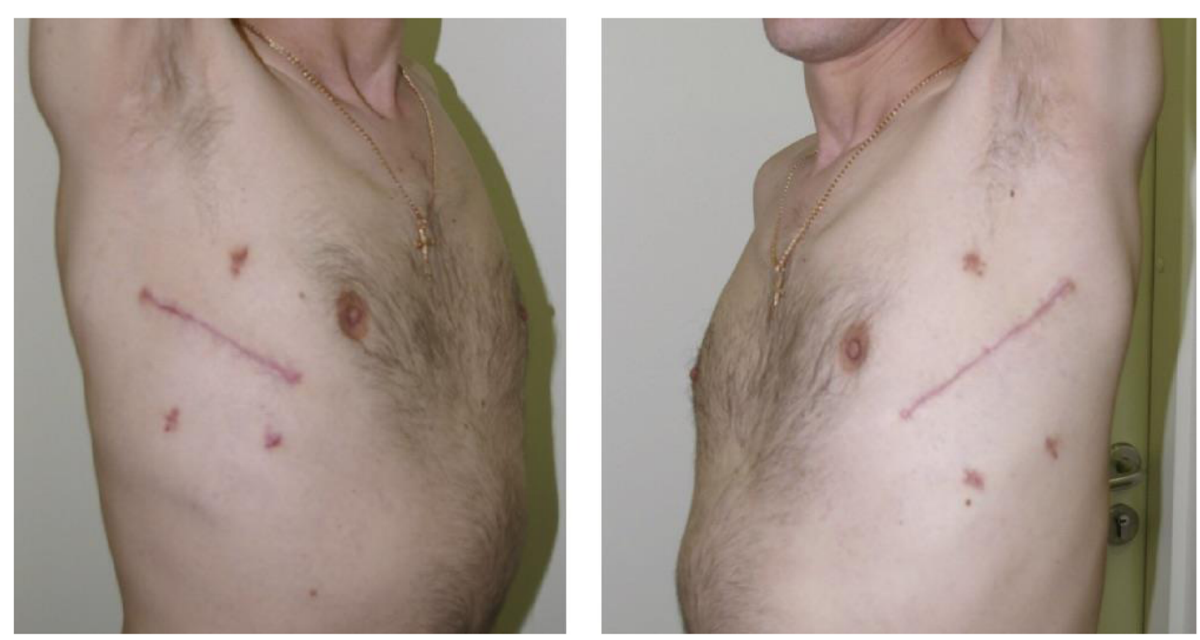

Fig. 4 Postoperative scars 


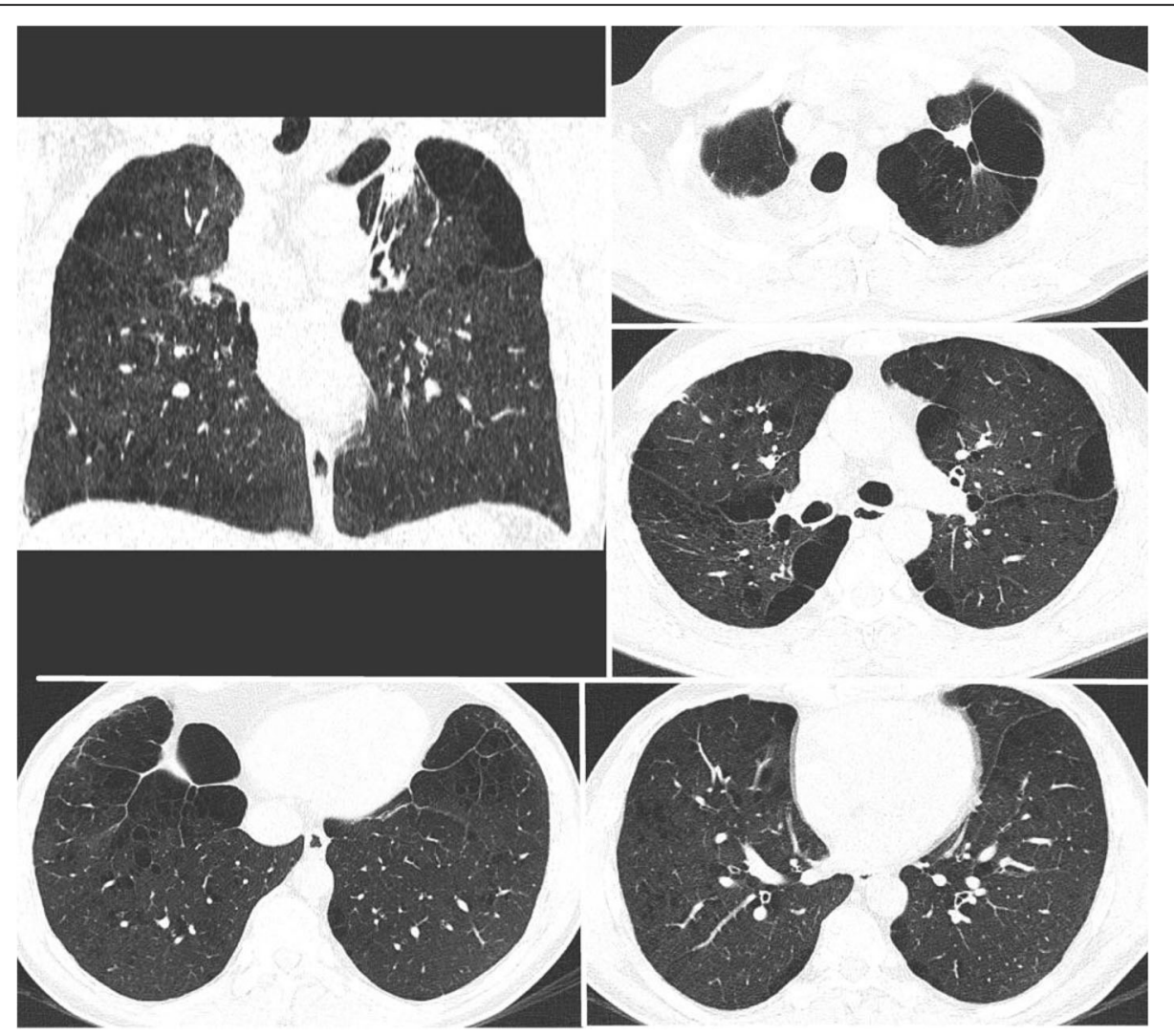

Fig. 5 Chest CT scan 6 years past surgery. Both lungs are extended and fulfills hemithorax volume. In upper and middle sections of both lungs bullae up to $6 \mathrm{~cm}$ in diameter are visualized

follow-up period it is possible that no recurrence of giant bullae manifests, which underlines the efficacy of surgical treatment of patients with VLS.

VLS in patients with COPD is complicated by significant reduction in healthy lung tissue, and is often accompanied by severe respiratory function morbidity. VATS giant bulla resection should be accompanied by proper pharmacological therapy and strict respiratory exercise regimen. Surgical excision of giant bullae significantly reduce the ratio of pleural cavity to lung volume, so we recommend gradual expansion with controlled pneumoperitoneum to reduce risk of postoperative complications and spontaneous pneumothorax.

In the presented case report, primarily a two-stage surgery was planned, but due to postoperative complications, urgent surgery and second stage surgery were performed $26 \mathrm{~h}$ after primary surgery. It is important to note, that a single stage bilateral bullectomy is recommended, with simultaneous controlled peritoneum and pleural drainage. This allows to reduce the adverse effects of lung volume reduction.

Table 1 Examination results

\begin{tabular}{|c|c|c|c|}
\hline & Prior surgery & A month past surgery & 5 years follow-up \\
\hline Leukocytes & $9,8 \times 10^{9} / \mathrm{L}$ & $15,0 \times 10^{9} / \mathrm{L}$ & $7,9 \times 10^{9} / \mathrm{L}$ \\
\hline Arterial-blood gas (ABG) & pCO2 37,4; pO2 73; & pCO2 37,6; pO2 78; & pCO2 36,5; pO2 82; \\
\hline \multirow[t]{3}{*}{ Spirometry } & $\begin{array}{l}\text { VC 2, } 77 \text { L, 53\%; FEV1 1,54 L, 37\%; } \\
\text { FEV1 NC 69\% }\end{array}$ & VC $1.43 \mathrm{~L}, 27 \%$ & VC -3.71 L (69\%), \\
\hline & \multirow[t]{2}{*}{ Severe COPD } & FEV1 1,51 L, 36\%; FEV1NC 113\% & $\begin{array}{l}\text { FEV1-1.84L (45.3\%), FEV1/NC = 49,6\%, } \\
\text { MEF 25/75-1.11 L (25.5\%) }\end{array}$ \\
\hline & & Severe COPD & Severe COPD \\
\hline $6 \mathrm{MWT}$ & $422 \mathrm{~m}$ & $403 \mathrm{~m}$ & $550 \mathrm{~m}$ \\
\hline CAT, mMRC GOLD 2 [10] & mMRC 2 & mMRC 1 & mMRC 1 \\
\hline
\end{tabular}




\section{Conclusion}

In conclusion, surgical resection of giant emphysematous bullae and appropriately prescribed therapy (drug treatment and hygiene regime) allowed us to achieve a positive effect and maintain the patient's life quality for a long time [15], verified by postoperative respiratory function indicators, and radiological imaging. It is important to plan a single-stage surgical intervention with compensation of lung volume reduction (controlled pneumoperitoneum, pleural cavity draining), appropriate pharmacological therapy and respiratory exercises to maintain the positive effect of VLS treatment.

\section{Abbreviations \\ COPD: Chronic obstructive pulmonary disease; NYHA: New York Heart Association; CT: Computed Tomography; ERS/ATS: European Respiratory Society/ American Thoracic Society; MRC: Medical Research Council; mMRC: Modified Medical Research Council; VATS: Video Assisted Thoracic Surgery; ECG: Electrocardiography; 6MWT: Six Minutes Walking Test: GOLD: Global Inititiative For Chronic Obstructive Lung Disease}

\section{Acknowledgements}

None.

\section{Authors' contributions}

Dmitry Borisovich Giller - consulting, surgical treatment, work design, manuscript revising. Galina Vladimirovna Scherbakova - conservative treatment, consulting, diagnostics, literature review. Boris Dmitrievich Giller translation, manuscript preparation, work analysing. Arkadyi Leybovich Khanin - long-term results collection, treatment control, conservative treatment. Vladimir Nikolaevich Nikolenko - surgical treatment, work analysing, review. Mikhail Yegorovich Sinelnikov - translation, long term results collection, review, final manuscript preparation. The authors read and approved the final manuscript.

\section{Funding}

None.

Availability of data and materials

Data and material available upon request.

\section{Ethics approval and consent to participate}

Ethics approval was obtained.

\section{Consent for publication}

Informed consent for publication was obtained.

\section{Competing interests}

None.

\section{Author details}

M.I. Perelman Department of Phthisiopulmonology and Thoracic Surgery, I.M. Sechenov First Moscow State Medical University (Sechenov University), 119991, 8 Trubeckaya str., Moscow, Russia. ${ }^{2}$ Department of Phthisiopulmonology, Novokuznetsk State Institute of Postgraduate Medical Education - a branch of FSBEI APE PO RMACPE of the Ministry of Health, 5 Stroiteley Pr, Novokuzneck 654005, Russia. ${ }^{3}$ Human Anatomy Department, I.M. Sechenov First Moscow State Medical University (Sechenov University), 119991, 8 Trubeckaya str, Moscow, Russia. ${ }^{4}$ Institute for regenerative medicine, I.M. Sechenov First Moscow State Medical University (Sechenov University), 119991, 8 Trubeckaya str, Moscow, Russia.

Received: 24 March 2020 Accepted: 20 July 2020

Published online: 29 July 2020

\section{References}

1. Global initiative for chronic obstructive lung disease strategy for the diagnosis, management and prevention of chronic obstructive pulmonary disease: an Asia-Pacific perspective. Respirology. 2005;10(1):9-17Wiley; Available from:. https://doi.org/10.1111/j.1440-1843.2005.00692.x.

2. Marchetti N, Criner G. Surgical approaches to treating emphysema: lung volume reduction surgery, Bullectomy, and lung transplantation. Semin Respir Crit Care Med. 2015;04(36):592-608.

3. Kim SW, Kim D. Management of long-term persistent air leakage developed after bullectomy for giant bullous lung disease associated with neurofibromatosis type 1. J Thorac Dis. 2016;1 (8):E140-3.

4. Kadowaki T, Yano S. Autobullectomy in a patient with COPD. Intern Med. 2018;8(57):1179.

5. Im Y, Faroogi S, Mora A. Vanishing lung syndrome. Baylor Univ Med Center Proc. 2016;29(4):399-401.

6. Sunanda H, Razaque MA. Bilateral vanishing lung syndrome. J Medi Soc. 2010;3(24):155-6.

7. Vij AS. A rare case of vanishing lung syndrome. J Assoc Physicians India. 2014;12(62):51-3.

8. Little BC. Classification of functional capacity and objective assessment. Am Heart Assoc. 1994:253-6

9. Lareau S. Standards for the diagnosis and treatment of patients with COPD: a summary of the ATS/ERS position paper. Eur Respir J. 2008;6(23):932-46.

10. Findlay JM. Radiological presentation of a giant bulla as a tension pneumothorax. J Emerg Med. 2012;3(43):e211-3.

11. Pearson MG, Ogilvie C. Surgical treatment of emphysematous bullae: late outcome. Thorax. 1983;2(38):134-7.

12. Schipper PH. Outcomes after resection of giant emphysematous bullae. Ann Thorac Surg. 2004;3(78):976-82

13. Fishman RMS, Grippi MA, Elias JA, Fishman JA, Kotloff RM, Fishman Al. Fishman's pulmonary diseases and disorders 5th edMcGraw-Hill Medical; 2015.

14. Gian FM, Franca MA, Alfredo M, Antonio P. Treatment by VATS of giant bullous emphysema: results. Eur J Cardiothorac Surg. 1998;13:66-70.

15. Wakabayashi A. Thoracoscopic technique for management of giant bullous lung disease. Ann Thorac Surg. 1993;3(56):708-12.

\section{Publisher's Note}

Springer Nature remains neutral with regard to jurisdictional claims in published maps and institutional affiliations.

\section{Ready to submit your research? Choose BMC and benefit from:}

- fast, convenient online submission

- thorough peer review by experienced researchers in your field

- rapid publication on acceptance

- support for research data, including large and complex data types

- gold Open Access which fosters wider collaboration and increased citations

- maximum visibility for your research: over $100 \mathrm{M}$ website views per year

At BMC, research is always in progress.

Learn more biomedcentral.com/submissions 